\title{
Spasialisasi Dan Konglomerasi Media Pada Kelompok Kompas Gramedia
}

\author{
Elisabeth Rotua Simamora \\ (elisabethrotuas@yahoo.com) \\ (Magister Ilmu Komunikasi FISIP UNDIP)
}

\begin{abstract}
Spatialization is a part of the political economy. Media realize theta it is the process of overcoming the constraints of space and time through its two forms of renewal of corporate power, that is horizontal and vertical concentration. The growth of media is becoming the trend of economy and politic in the media industry and expanding the corporae ownership. By having a literatures study used, the writer found that mass media development nowdays is not only the company's abilities to provide and satisfy the information and entertainment needs which match the society needs, however it also developes the other business interest's orientations.
\end{abstract}

Keywords : Media, Politic Economy, Spatialization

\section{Pendahuluan}

Kunci pada karakter institusi media yang tidak biasa adalah bahwa aktivitasnya tidak terpisahkan secara ekonomi maupun politik, sekaligus sangat tergantung pada teknologi yang terus menerus berubah. Aktivitas ini melibatkan produksi barang dan layanan yang seringkali bersifat pribadi dan publik. Karakter publik media diturunkan terutama dari fungsi politik media dalam demokrasi, tetapi juga fakta bahwa informasi, budaya dan gagasan dianggap sebagai kepemilikan kolektif. Hal tersebut tercermin dalam berbagai mekanisme untuk mendukung, melindungi, atau membatasi media atas nama apa yang seharusnya merupakan "kepentingan publik". Terlepas dari hal ini media secara umum harus beroperasi secara keseluruhan atau sebagian menurut dikte ekonomi pasar. Bahkan dalam aspek ini, media dapat menarik perhatian pemerintah untuk alasan yang sama yang membuat bisnis pribadi menjadi subjek berbagai bentuk regulasi hukum dan ekonomi.

Mosko membagi Ekonomi Politik dalam tiga konsep, yaitu: komodifikasi, spasialisasi, dan strukturasi. Komodifikasi merupakan proses transformasi barang dengan nilai tukarnya, spasialisasi yang merupakan transformasi jarak dengan waktu atau proses perpanjangan institusional, dan strukturasi, proses struktur dengan lembaga sosial (Mosco, 2009: 138). Ketiga konsep ini saling berkaitan dimana setiap perusahaan atau sistem media akan terus menciptakan inovasi media yang diikuti dengan teknologi media sehingga menghasilkan transformasi barang dengan nilai tukarnya, sehingga menyebabkan adanya perluasan jarak dan waktu yang disebabkan oleh pemenuhan kebutuhan masyarakat dan pada akhirnya mempengaruhi struktur dengan lembaga sosial.

Sistem media (media system) mengacu pada serangkaian media massa aktual dalam suatu masyarakat nasional, terlepas dari fakta bahwa mungkin tidak ada hubungan formal antar elemen-elemennnya. Didalam sistem media, jenis-jenis tertentu yang berbeda ditemukan berdasarkan teknologi media yang berbeda: cetak, televisi, radio, rekaman musik, internet, telekomunikasi dan sebagainya. Namun, jenis-jenis ini sering dibagi-bagi lagi 
menjadi "bentuk media" yang berbeda-beda, misalnya media cetak menjadi buku, majalah atau surat kabar, media film dapat mengacu pada sinema, video, DVD dan siaran televisi. Ini semua merupakan alatalat distribusi yang berbeda, seringkali berupa organisasi dan bisnis yang berbeda, meskipun biasanya terdapat suatu bentuk integrasi vertikal. Integrasi Vertikal ini berkembang sesuai dengan kemajuan teknologi media massa. Dengan kata lain, penyebaran informasi media massa akan menyesuaikan teknologi informasi baru.

Secara umum, konsentrasi media telah dibedakan menurut bentuk "horizontal" dan "vertikal". Konsentrasi vertikal (vertical concentration) merujuk pada pola kepemilikan yang meluas melalui tingkatan yang berbeda dari produksi dan distribusi (misalnya studio film yang memiliki jaringan bioskop) atau secara geografi (surat kabar nasional membeli surat kabar lokal). Konsentrasi horisontal (horizontal concentration) merujuk pada gabungan (merger) di dalam pasar yang sama (misalnya antara dua lembaga surat kabar lokal atau nasional yang saling bersaing atau antara jaringan telepon dengan kabel). Kedua proses ini terjadi dalam skala besar di sejumlah negara, walaupun efeknya mungkin berubah oleh pilihan media yang terus menerus serta munculnya media baru. Keragaman seringkali dilindungi oleh kebijakan publik melawan "kepemilikan lintas media" (media berbeda yang dimiliki dan dijalankan oleh perusahaan yang sama, terutama didalam pasar geografis yang sama). Media juga dapat terlibat dalam konsentrasi horizontal, melalui penggabungan perusahaan di industri yang berbeda, sehingga surat kabar atau saluran televisi dapat dimiliki oleh bisnis non media. Hal ini tidak secara langsung mengurangi keragaman media, tetapi dapat menambah kekuatan media massa dan memiliki dampak yang lebih luas bagi periklanan (McQuail, 2012: 256).

Jumlah media massa di Indonesia sangat banyak. Namun, ada 12 grup media yang mendominasi. Para Peneliti dari Centre for Innovation Policy and Governance (CIPG) mengumumkan hasil riset bahwa ada 12 grup besar yang menguasai hampir seluruh kanal media di Indonesia. "Hasil penelitian kami bekerja sama dengan lembaga non pemerintah Hivos Asia Tenggara menunjukkan bahwa ada 12 grup media besar yang menguasai Indonesia," kata Peneliti CIPG Yanuar Nugroho seperti yang dilansir dari Yahoo. 12 grup tersebut antara lain MNC Media Group, Jawa Pos Group, Kompas Gramedia Group, Mahaka Media Group, Elang Mahkota Teknologi, CT Corp, Visi Media Asia, Media Group, MRA Media, Femina Group, Tempo Inti Media dan Beritasatu Media Holding (http://www.infospesial.net/315/12-mediabesar-kuasai-indonesia/).

Kompas Gramedia Group, merupakan salah satu grup media terbesar di Indonesia. Perkembangan dari Kompas Gramedia Group yang awal kelahirannya dimulai dari terbitnya majalah bulanan Intisari pada 17 Agustus 1963, oleh Petrus Kanisius dan Jacob Oetama, bersama J. Adisubrata dan Irawati SH. Hampir 3 tahun kemudian, diterbitkan surat kabar Kompas yang hingga hari ini, harian Kompas dapat kita nikmati. Kompas Gramedia group melakukan komodifikasi yakni menstransformasi nilai guna menjadi nilai tukar. Kompas Gramedia Group untuk dapat mempertahankan bisnis perusahaannya melakukan spasialisasi. Spasialisasi yang dilakukan mengupayakan agar Kompas Gramedia Group dapat bertahan dan meningkatkan produk-produk media massa 
dan non media sehingga menembus batasbatas antar negara (borderless world).

Kompas Gramedia Group merupakan salah satu dari 12 media besar yang mendominasi di Indonesia. Untuk mempertahankan perusahaannya ini, Kompas Gramedia Group melakukan komodifikasi produk media massa, dan melakukan spasialisasi untuk mengatasi keterbatasan ruang dan waktu, sehingga mencapai globalisasi.

Studi Putaka, merupakan pembahasan yang berdasarkan pada buku-buku referensi atau berdasarkan hasil kegiatan ilmiah berupa penelitian ilmiah dengan menggunakan berbagai metode penelitian terdahulu yang bertujuan untuk memperkuat materi pembahasan.

\section{Pembahasan}

Istilah spasialisasi yang diperkenalkan oleh teoritis sosial Henri Lefebvre (1979) ini, merupakan sebuah proses untuk mengatasi keterbatasan ruang dan waktu dalam kehidupan sosial. Spasialisasi memiliki signifikansi khusus bagi ahli ekonomi politik komunikasi karena komunikasi adalah salah satu sarana utama dalam memperkenalkan spasialisasi ke seluruh masyarakat dan akibatnya spasialisasi membuat industri komunikasi sangat signifikan. Konsep lainnya dari sosiolog Anthony Giddens (1990) yang menggunakan istilah penjarakkan ruang dan waktu (time-space distanciation) untuk memahami bagaimana waktu dan ruang telah berkurang sebagai pengaruh pengendali di dunia.

\begin{tabular}{lr}
\multicolumn{1}{c}{ Mosco ingin } & memberikan \\
pemahaman mengenai & penggunaan \\
spasialisasi dalam penelitian & komunikasi, \\
khususnya untuk menunjukkan bagaimana & perusahaan-perusahaan \\
menggunakan
\end{tabular}

komunikasi untuk memperluas kekuasaan mereka melalui beragam bentuk konsentrasi. Adanya konsentrasi perusahaan memungkinkan perusahaan-perusahaan memiliki kontrol yang lebih baik atas produksi, distribusi, dan pertukaran komunikasi, dan juga membatasi kompetisi sehingga muncul keberagaman informasi dan hiburan di masyarakat. Ada dua macam konsentrasi. Pertama konsentrasi horisontal, terjadi ketika sebuah perusahaan media membeli saham yang besar di operasi media lainnya, tetapi tidak secara langsung berhubungan dengan bisnis utamanya, atau ketika mengambil saham besar di sebuah perusahaan di luar media. Kedua konsentrasi vertikal, terjadi ketika sebuah perusahaan media memperluas kekuasaan proses produksinya (Mosco, 2009:159-160).

Yang pada akhirnya ketika spasialisasi telah tercapai akan membuat globalisasi perusahaan. Seperti yang Tomlinson definisikan "Globalization refers to the rapidly developing process of complex interactions between societies, cultures, institutions and individuals world-wide. It is a social process which involves a compression of time and space, shrinking distances through a dramatic reduction in the time taken-either physically or representational- to cross them, so making the world seem smaller and in a certain sense bringing human being closer to one another. Atau dengan kata lain globalisasi mengacu pada proses berkembang pesat dari interaksi kompleks antara masyarakat, budaya, lembaga dan individu di seluruh dunia. Ini adalah proses sosial yang melibatkan komparasi ruang dan waktu, penyusutan jarak melalui pengurangan dramatis dalam waktu yang diambil-baik secara fisik atau representatif - untuk menyeberang mereka, sehingga membuat dunia tampak lebih kecil dan dalam arti tertentu membawa manusia lebih dekat 
dengan satu sama lain. Globalisasi juga mengacu pada hubungan semakin globalnya budaya, orang dan kegiatan ekonomi. Istilah ini juga dapat merujuk pada sirkulasi transnasional ide, bahasa, dan budaya populer.

Kompas Gramedia grup, terbentuk pada tahun 1963, dengan terbitnya majalah Intisari, dengan tujuan memberi bacaan bermutu dan membuka cakrawala masyarakat Indonesia. Saat itu, majalah ini tebit dengan tampilan hitam putih tanpa sampul, 128 halaman, dan mendapat sambutan baik dari masyarakat dan beroplah sampai dengan 11.000 exemplar. Tiga tahun kemudian, Surat Kabar Kompas diterbitkan sebagai koran untuk melawan pers komunis. Nama KOMPAS sendiri merupakan pemberian dari Presiden Indonesia Pertama yakni, Presiden Soekarno, yang artinya penunjuk arah.

\section{Berikut perkembangan Kompas Gramedia Group dalam melakukan spasialisasi untuk menciptakan produk- produk yang mengglobal: \\ Spasialisasi dan Globalisasi Kelompok Kompas Gramedia}

\section{Produk-produk industri Kompas Gramedia}

1. Surat Kabar

- Harian Kompas merupakan surat kabar nasional yang berkantor pusat di Jakarta. Harian Kompas terbit setiap hari dan memiliki beberapa rubrik diantaranya yaitu Berita Utama, Bisnis \& Keuangan, Humaniora, International, Opini, Politik \& Hukum, Sosok, Nama \& Peristiwa, Nusantara, Metropolitan, Olahraga. Berita-berita pada Harian Kompas biasanya bersifat nasional dan tidak hanya meliputi satu daerah saja.
- Tribun

Pers Daerah (Persda) merupakan surat kabar yang terbit setiap hari di bawah naungan Kompas Gramedia. Semula Persda hanya memiliki beberapa koran, diantaranya Serambi Indonesia (Aceh), Pos Kupang (Kupang), Bernas (Yogya), Bangka Pos (Bangka), Banjarmasin Post di Banjarmasin, Sriwijaya Pos (Sripo) di Palembang. Dengan konsep baru, Pers daerah memproduksi koran dengan brand Tribun. Dan Nama Tribun ini mulai diaplikasikan di Kalimantan Timur melalui harian Tribun Kaltim, Tribun Jabar di Jawa Barat, Tribun Lampung di Lampung, dan Tribun Timur di Sulawesi Selatan. Dan Pada Tahun 2011, Terbitlah Harian Umum Tribun Jogja setelah Harian Umum Bernas dilepas oleh Kompas Gramedia. Hal ini juga terjadi di Medan ketika Harian Umum Analisa keluar dari naungan Kompas Gramedia dan terbitlah harian Tribun Medan. Pada tahun 2012, Harian Umum Tribun Sumsel diterbitkan.

- Kontan, merupakan media mengenai investasi dan bisnis yang terbit dalam bentuk harian, mingguan, maupun bulanan (edisi khusus).

- Warta Kota merupakan salah satu surat kabar harian umum yang terbit di Jakarta, dengan tema bebas meskipun basisnya tetap pada berita perkotaan, dengan bahasan pada segala masalah yang terjadi ataupun berkaitan dengan persoalan perkotaan dan segala tingkah polah manusianya. Pilihan menu antara olahraga, selebritas, dan hot topics.

Harian Warta Kota dimaksudkan untuk menjadi media khas bagi warga Jakarta, Bogor, Depok, Tangerang, Bekasi, dan sekitarnya yang diharapkan dapat menjadi panduan warga dalam melihat dan menjalani hak-hak dan 
kewajibannya. Harian Warta Kota sekaligus menjadi jembatan sesama masyarakat, antara masyarakat dengan pemerintah (daerah dan wilayah) serta semua aparat yang memberikan pelayanan. Juga menjadi medium yang mempertemukan masyarakat sebagai konsumen dengan berbagai penyedia jasa pelayanan, perdagangan, industri, hiburan, dan semua kebutuhan mereka.

Pada Tahun 2008, Harian Berita Kota (Jakarta) terbit dibawah Naungan Kompas Gramedia. Isi berita tidak jauh berbeda dengan Warta Kota, hanya saja perbedaan terletak pada jumlah halaman dan harga per eksemplarnya.

- Harian Surya merupakan surat kabar yang terbit di daerah Jawa Timur. Basisnya hampir serupa dengan Harian Warta Kota di Jakarta. Beberapa rubrik diantaranya yaitu: Tunjungan Life, Malang Life, Jawa Timur, Citizen Reporter, Inter-Nas, Ekonomi Bisnis, Selebriti, E-Life, Suara Publik, Probis, Elektronika, Komunitas dan ulasan khusus olahraga.Perjalanan sejarahnya, Surya pernah menjangkau sebagian besar wilayah Indonesia timur seperti Kota Ujungpandang atau Makassar, NTB dan Provinsi Bali. Seiring berjalan waktu, ketika Surya tergabung dalam Tribun Grup, Surya fokus melayani pembaca di wilayah Jawa Timur saat ini.

2. Majalah

- National Geographic, merupakan majalah yang terbit setiap bulan. Berbeda dengan Intisari yang lebih banyak menyajikkan artikel mengenai berita yang sedang hangat dibicarakan, National Geographic lebih kepada berita-berita mengenai lingkungan dan alam yang disajikan dengan foto-foto yang menarik.Berita nasional yang sedang terjadi pun tidak luput menjadi perhatian majalah ini.

- National Geographic Kids, merupakan majalah National Geographic untuk anak-anak yang terbit bulanan. Banyak pengetahuan yang wajib anak-anak ketahui. Rubrik-rubriknya adalah Aneh Tapi Nyata, Belum Tahu,Kan ?, HewanHewan Hebat, Olahraga Hahaha, Luculucuan, Tebak Kocak, Omong,Dong, dan Karya Kamu.

- Potret Negeriku, majalah Potret Negeriku terbit bulanan. Yang membuatmu lebih tahu keanekaragaman budaya Indonesia.

- Intisari adalah majalah bulanan yang pertama kali terbit di Indonesia pada tahun 1963. Majalah ini berisi rubrik yang menginspirasi.

- Princess, majalah Princess terbit bulanan. Tokoh-tokohnya berasal dari film-film Disney. Ada Snow White, Ariel, Pocahontas, Rapunzel, Cinderella dan kawan-kawan

- Barbie, majalah Barbie terbit bulanan. Tokohnya adalah Barbie dan kawankawan. Banyak sekali permainan serta aktivitas. Ada bonus berupa hadiah.

- Cars, majalah Cars terbit setiap bulan. Majalah ini berasal dari film Disney Cars.

- Bobo merupakan majalah untuk anakanak yang terbit setiap hari Kamis. Majalah yang biasanya terdiri dari 56 halaman ini berisi mengenai rubrikrubrik yang menarik anak-anak seperti pengetahuan dan cerita-cerita.

- Bobo Junior, merupakan majalah untuk anak-anak terbit setiap hari Rabu. Banyak permainan dan aktivitas.

- Hai, adalah majalah mingguan dan diperuntukkan untuk para remaja pria yang duduk di bangku SMP sampai SMA. Informasi yang diberikan 
merupakan segala hal yang berkenaan dengan dunia remaja seperti memuat segala artikel yang berkenaan dengan gaya hidup. Mulai dari musik, film, pendidikan, tempat nongkrong, fesyen, teknologi, olahraga, psikologi, pendidikan seks, dan tentu saja cerita pendek dan komik.

- Kawanku, adalah majalah bagi para remaja putri yang berusia antara 13 sampai 16 tahun. Kawanku terbit setiap hari minggu. Informasi yang diberikan biasanya mengenai masalah fesyen, psikologi, cerpen, film, musik, dan selebritas.

- Girls Cantik dan Cerdas, merupakan majalah anak perempuan Dari SD sampai SMP, Dari umur 8 sampai 14 tahun. Di majalah Girls, ada rubrik MailBox, Our Guest, Ssstt, Jendela, Bintang Bintang, Dan lain lain

- Nova, merupakan sebuah tabloid wanita. Tabloid ini memberikan informasi seputar wanita dan juga peristiwa-peristiwa yang terjadi di sekitar kita. Misalnya ada rubrik kecantikan, keluarga, kesehatan, busana, griya dan juga informasi mengenai para selebritis atau orang-orang sukses dan terkenal.

- CHIP, merupakan majalah komputer yang terbit setiap bulan satu kali. Majalah ini berisi informasi terbaru dari industri komputer, hasil tes perangkat keras dan perangkat lunak, serta tip dan trik. CHIP juga mempresentasikan gambaran aktual dari layanan online yang ada dan memberikan bantuan serta panduan bagi pengguna dalam memasuki dunia maya. Biasanya pembeli akan mendapatkan DVD-ROM yang berisi perangkat lunak pilihan redaksi.

- Info Komputer, merupakan majalah komputer yang terbit setiap bulan. Info
Komputer mengulas beragam informasi dari industri komputer, hasil pengujian perangkat keras dan perangkat lunak, tip dan trik komputer, tutorial, serta menyediakan segmen khusus untuk industri berskala enterprise.

- Angkasa, merupakan majalah bulanan yang memberikan informasi mengenai pesawat dan kedirgantaraan. Angkasa juga menerbitkan by product Angkasa Edisi Koleksi dan Commando yang lebih menjelaskan lebih detail tentang aspek kesenjataan dan sejarah dalam dunia kemiliteran.

- What Hi-Fi? merupakan majalah yang ditujukan bagi para peminat audio video dan home cinema. Majalah bertiras 26.000 eksemplar ini terbit setiap bulan dengan menyajikan berbagai informasi dengan lingkup bahasan seputar informasi produk $\mathrm{Hi}-\mathrm{Fi} \&$ Home Cinema dan informasi penunjang lainnya. What Hi-Fi juga dapat dijadikan panduan belanja dan pengaturan audio video. Selain itu dalam setiap edisinya majalah ini menyajikan tips, trik, dan solusi seputar masalah sound and vision.

- $\quad$ PC Plus, merupakan tabloid yang berisi artikel dan berita perkembangan dunia Teknologi Informasi. Jadi pembahasannya tidak hanya seputar komputer saja akan tetapi lebih luas lagi teknologi informasi.

- HotGame, merupakan majalah bagi penggemar permainan yang terdapat dalam komputer. Majalah ini terbit setiap bulan. Informasi yang diberikan berupa permainan baru berikut penjelasan akan cara memainkannya.

- Saji, merupakan tabloid dwi mingguan yang terbit setiap hari Rabu dan bertiras 356.750 eksemplar. Lingkup bahasannya yang tidak lain membahas seputar resep makanan dengan aneka 
variasi juga menyajikan informasi dan tips tentang pembuatan makanan langsung jadi, sekaligus cara penggunaan peralatan masak yang benar.

- Sedap, merupakan majalah bulanan yang terbit pada hari Rabu minggu pertama. Majalah bertiras 90.250 eksemplar ini mengupas tuntas seputar resep masakan, lengkap dengan tips pengolahan makanan, sampai seni penyajian konsultasi gizi, dan manajemen boga.

- Bola, merupakan tabloid yang terbit satu minggu tiga kali yaitu pada hari Senin, Kamis dan Sabtu. Tabloid ini ditujukan pada para penggemar bola. Informasi yang diberikan meliputi dunia bola baik dalam maupun luar negri.

- Soccer, adalah tabloid yang ditujukan kepada para penggemar sepak bola. Tabloid mingguan bertiras 345.953 eksemplar ini terbit setiap hari Sabtu, dan beredar hari Kamis. Lingkup bahasan tabloid ini yang menyajikan informasi seputar sepak bola dunia, khususnya Eropa sebagai menu utama. Selain itu juga berita-berita dan gosip, data dan ulasan lengkap pertandingan, prediksi dan bursa taruhan, serta informasi dibalik permainan suatu pertandingan . Tak ketinggalan pula style yang berisi panduan bagi para penggemar sepak bola yang ingin mengekspresikan dirinya. Sisi humanistik para pemain dari berbagai klub, juga disajikan dalam tabloid ini.

- Motor Plus, adalah tabloid bertiras 236.200 eksemplar yang dutjukan bagi bagi para pemilik maupun penggemar sepeda motor. Tabloid ini terbit setiap hari Sabtu dan beredar pada hari Rabu. Motorplus menyajikan informasi dengan lingkup bahasan seputar modifikasi, olahraga, bisnis sepeda motor, dan tips dalam berkendara.

- Digital Camera Indonesia, ialah sebuah majalah yang berisi tentang dunia fotografi dan asas-asas pemotretan' majalah ini lahir tahun 2013

- Citra adalah salah satu tabloid di Indonesia yang memuat tema musik, televisi dan hiburan dan diterbitkan oleh Kelompok Kompas Gramedia. Citra pernah menjadi tabloid hiburan yang sangat populer dan disegani para selebritis dan kalangan hiburan, terutama setelah tabloid serupa, Monitor, dicabut izin terbitnya. Namun kemudian tabloid ini ternyata tidak mampu bersaing dengan tabloid serupa lainnya dan tidak terbit lagi sejak Desember 2004.

- Otomotif, merupakan tabloid yang dikhususkan kepada para penggemar otomotif, para pemilik kendaraan bermotor dan dealer. Tabloid ini terbit pada hari Senin dan beredar pada hari Kamis. Otomotif memberikan informasi mengenai seputar bisnis, teknologi, modifikasi dan olahraga otomotif, lengkap dengan tips bagi pembacanya.

- Idea, adalah majalah yang terbit setiap bulan yang ditujukan bagi pembaca yang menyukai desain interior, dan ingin mendapatkan inspirasi menata rumah. iDEA memiliki tagline "ide kreatif seputar rumah", berdiri pada tanggal 9 Februari 2004 dan kini telah memiliki beberapa produk turunan diantaranya adalah Majalah Renovasi, www.ideaonline.co.id, iDEAbooks, dan yang terbaru adalah iDEA ipad yang baru launching pada tanggal 19 Februari 2011. iDEA akan mengembangkan diri menjadi media yang aktif di social networking dan bagian dari pengembangan Social Media Gramedia Majalah. 
- Gaya Hidup Sehat, ialah tabloid yang terbit setiap bulan yang berisi beberapa informasi seputar kesehatan, Tabloid ini terbit pada tahun 2003

- InfoKomputer, terbit setiap bulan yang berisi informasi seputar dunia komputer, Tablotd ini terbit pertama pada tanggal 14 Januari 1987

- Forsel, merupakan majalah bulanan yang memberikan informasi tentang selular.

- Oto Plus, merupakan tabloid mingguan yang terbit setiap hari Senin. Oto Plus memberikan informasi yang berhubungan dengan sepeda motor, modifikasi, olahraga dan tips dalam berkendara. Tabloid ini berkantor pusat di Surabaya.

Spasialisasi Horisontal, dengan meningkatnya teknologi (dengan ditemukannya komputer - internet, televisi, radio), Kelompok Kompas Gramedia mengadakan kerjasama dibidang horizontal. Berikut perusahaan-perusahaan industri di bidang media massa.

1. Televisi,

- Kompas TV, Kompas TV merupakan stasiun televisi yang menampilkan kekayaan alam Indonesia. Televisi ini penuh inspiratif dan berusaha untuk mencerdaskan bangsa dengan program-program yang edukatif. Sebenarnya Kompas TV ini hadir menggantikan stasiun televisi yang pernah dimiliki oleh Kompas Gramedia, yaitu TV7. Sejak semua saham TV7 dibeli oleh pihak Trans Corp yang berdiri dibawah kepemimpinan Chairul Tanjung pada tahun 2006 dan nama TV7 diganti menjadi Trans7, maka Kompas Gramedia tidak lagi memiliki perusahaan televisi. Namun pada tahun 2011, Kompas Gramedia meluncurkan kembali stasiun televisi yang selama ini diinginkan oleh pendiri Kompas Gramedia, Jakob Oetama.

- Ada 10 televisi lokal berjaringan dengan Kompas TV yaitu, KTV (Jabodesertabek), STV (Bandung), TV Borobudur (Semarang), BCTV (Surabaya), MOSTV (Palembang), Khatulistiwa TV (Pontianak), ATV (Malang-Batu), Dewata Bali TV (Denpasar), RBTV (Yogyakarta), dan Makassar TV (Makassar).

- televisi kabel (jaringan berbayar) bergabung dengan Aora, Centrin TV, First Media, Groovia TV, OrangeTV, Skynindo, TelkomVision, YesTV, dan Max3.

2. Radio

- Radio Sonora, merupakan stasiun radio yang memiliki komitmen untuk mewujudkan visi sebagai radio informasi dan hiburan yang paling diminati oleh pendengar dan pemasang iklan serta untuk mengantisipasi berbagai perubahan yang terjadi di masyarakat. Radio Sonora memiliki cabang di beberapa kota seperti Surabaya, Yogyakarta, Palembang, Pangkal Pinang, Pontianak, Palangkaraya, Semarang, Solo, Bandung, Purwokerto, Cirebon, Banjarmasin, Serambi Aceh, Malang, Bali, Bandar Lampung, Medan, dan Manado.

- Motion Radio Motion Radio adalah stasiun radio yang berasal dari Jakarta. Stasiun radio ini didirikan pada tahun 90-an dengan nama Safari Bisnis FM, lalu berganti nama menjadi Jakarta News FM, lalu berganti nama lagi menjadi Otomotion FM dan sampai sekarang menggunakan nama Motion Radio. 
- Smart FM, merupakan Stasiun Radio yang berasal dari Jakarta. Stasiun radio ini didirikan pada tanggal 1 Mei 1996. Radio Smart FM memiliki berbagai Cabang di beberapa kota seperti Surabaya, Semarang, Palembang, Manado, Makassar, Banjarmasin, Medan, dan Balikpapan.

- RAL FM, merupakan Stasiun Radio yang memiliki komitmen untuk mewujudkan visi sebagai Radio konten muslim yang paling diminati oleh pendengar serta pemasang iklan dan untuk mengantisipasi perubahan yang terjadi di masyarakat Kota Manado.

- Montini FM Adalah Stasiun Radio yang berasal dari Manado. Radio ini mewujudkan visi sebagai Radio Hiburan yang Paling diminati Pendengar di Kota Manado. Stasiun Radio ini didirikan pada tahun 1974 dengan nama Radio Veritas, kemudian pada tahun 1995 Berganti nama Menjadi 'Radio Montini' dan Sampai Sekarang Menggunakan nama Radio Montini FM.

3. Jaringan Percetakan, Gramedia membutuhkan percetakan. Perusahaan yang bergerak dibidang percetakan akan membantu Gramedia dalam mencetak media cetak yang diproduksi setiap harinya.

Gramedia Printing Group

- PT. Gramedia Printing: Jl. Palmerah Selatan 22-28, Jakarta 10270. Telp: 021-5480888, 5483008. Fax: 0215323662.

- PT. Gramedia Cikarang Plant: Jl. Angsana Raya Blok A2 No.1, Delta Silicon Industrial Park, Lippo Cikarang - Bekasi 17550. Telp: 02130002288. Fax: 021-30002287.
- PT. Gramedia Bandung Plant: Jl. Raya Rancaekek Km.24, Kawasan Industri Dwipapuri Abadi Kav.D3D5, Rancaekek, Sumedang - Jawa Barat. Phone: 022-7780049, 7780051. Fax: 022-7780050.

- PT. Antar Surya Jaya : Jl. Rungkut Industri III No.68 \& 70 SIER, Surabaya 60923. Telp: 031-8475000, 8419000. Fax: 031-8470600.

- PT. Bawen Mediatama: Jl. Gatot Subroto No.26, Bawen 50661 Semarang. Telp: 0298-591487, 593600. Fax: 0298-592886.

- PT. Medan Media Grafikatama: Jl. Pelita Raya No.46, Dusun III, KIM Star Tanjung Morawa B, Tanjung Morawa, Deli Serdang 20362, Sumatera Utara. Telp: 061-7946584, 7946925. Fax: 061-7946923.

- PT. Gramedia Bali Plant: Jl. Prof. Ida Bagus Mantra No.88A, Ketewel, Gianyar - Bali 80582. Telp: 0361295560, 295570. Fax: 0361-295571.

\section{Jaringan Penerbit Buku}

- Gramedia Pustaka Utama

- Penerbit ini mengkonsentrasikan diri untuk menggarap dua bidang utama, yakni fiksi dan non-fiksi. Bidang fiksi dibagi menjadi fiksi anak-anak dan pra-remaja, remaja, dewasa. Bidang non-fiksi dibagi menjadi humaniora, pengembangan diri, bahasa dan sastra Indonesia, bahasa Inggris/ELT, kamus dan referensi, sains dan teknologi, kesehatan, kewanitaan (masakan, busana), dsb. Contoh terbitan bidang fiksi yang diterbitkan adalah novel Karmila, karya Marga T. Sedangkan untuk buku non-fiksi pertama adalah Hanya Satu Bumi, yang ditulis oleh Barbara Ward dan René Dubois (diterbitkan bekerjasama dengan Yayasan Obor). 
Yang kemudian disusul oleh buku seri anak-anak pertama Cerita dari Lima Benua, dan kemudian seri-seri yang lain.

- Elex Media Komputindo

Penerbit buku ini yang semula dikhususkan untuk menerbitkan buku-buku di bidang teknologi, terutama teknologi informasi dan komputer. Namun, kini Elex juga menerbitkan buku-buku seri motivasi.

- Penerbit Buku Kompas

Penerbit ini merupakan penerbitan yang banyak menerbitkan kumpulan artikel para penulis terkemuka yang pernah dimuat di koran Kompas, konsentrasinya di non-fiksi. Juga banyak menerbitkan karya para penulis terkenal terutama di bidang sosial-politik, biografi, atau nasional.

- Kepustakaan Populer Gramedia (KPG) Penerbit ini berkonsentrasi menerbitkan buku-buku populer, termasuk komik non-fiksi (isinya adalah tulisan non-fiksi atau ilmu pengetahuan yang dibuat komik).

- Bhuana Ilmu Populer (BIP) Penerbit ini mengkhususkan diri pada buku anak-anak, kesehatan, motivasi, parenting, fiksi dan non fiksi

- Gramedia Widiasarana Indonesia (Grasindo) Salah satu penerbit yang pada awalnya berkecimpung di dunia pendidikan, namun kini mengembangkan diri dengan menerbitkan buku-buku motivasi, fiksi dan non fiksi.

- M\&c Penerbit ini berkonsentrasi menerbitkan komik dan manga.

- Level Comics Penerbit ini lebih berkonsentrasi menerbitkan komik dan manga untuk dewasa.

\section{Spasialisasi Vertikal}

Spasialisasi Vertikal, dimana Kompas memperluas perusahaannya namun bergerak di bidang yang berbeda dengan perusahaan asal, yakni perusahaan media massa.

\section{Event Organizer}

Dyandra Promosindo, merupakan perusahaan penyelenggara pameran yang telah mengadakan lebih dari 150 pameran berskala nasional dan internasional, antara lain: Indonesian International Motor Show, Mega Bazaar Computer, Festival Komputer Indonesia, Indocomtech, Bobo Fair, Indonesian Book Fair, FOCUS (Pameran Fotografi dan Produk Digital), Indonesian Cellular Show, dll. Saat ini Dyandra memiliki beberapa anak perusahaan yang bergerak di bidang yang terkait dengan industri pameran, yaitu:

- PT. Dyamall Graha Utama/E-Mall,

- PT. Dyandra Communication/Dyacomm (Advertising Agency),

- PT. Samudra Dyan Praga (Exhibition Contractor),

- PT. Kerabat Dyan Utama (Radyatama)

- Debindo Mitra Dyantama

- Gramedia Expo, Surabaya

- Venue Magazine

- PT. Visi Lintas Film (Caldecott)

- Bali Nusa Dua Convention Center

1. Jaringan Hotel

- Hotel Santika Premiere, memiliki sejumlah lokasi di Jakarta, Bandung, Bali, Malang, Manado, Semarang, dan Medan.

- Hotel Santika, memiliki sejumlah lokasi di Balikpapan, Bandung, 
Bogor, BSD City, Cirebon, Bali, Makassar, Pontianak, Semarang, Bangka, Surabaya, Lombok, Bengkulu, dan Tasikmalaya.

- Amaris Hotel, berlokasi di Ambon, Banjarmasin, Bandung, Bogor, Cirebon, Yogyakarta, Palangkaraya, Makassar, Bekasi, Semarang, Jakarta, Pekanbaru, Palembang, Samarinda, Gorontalo, Malang, Bali, dan Singapura.

- The Kayana \& The Samaya, berlokasi di Bali

- Royal Ambarukmo di Yogyakarta

2. Industri

PT. Graha Kerindo Utama: merupakan industri consumer goods yang memproduksi tissue dengan brand: Tessa, Dynasty dan Multi.

3. Pendidikan

- Universitas Multimedia Nusantara

Adalah sebuah universitas yang berdiri pada tanggal 20 November 2006. Universitas yang berlokasi di daerah Scientia Garden, Summarecon Serpong, Tangerang ini memiliki fokus pendidikan pada ICT (Information Communication and Technology).
- $\quad$ ELTI Gramedia

ELTI (English Language Training International) Gramedia adalah Lembaga Pendidikan Bahasa Inggris yang tersebar di beberapa kota di antaranya Jakarta, Bogor, Bandung, Yogyakarta, Solo, Purwokerto, dan Lampung. ELTI bergabung dengan Kompas Gramedia pada tahun 1989. Pada tanggal 9 Juni 2011 ELTI Gramedia meluncurkan program Franchise ELTI untuk pengembangan bisnisnya.

4. Publisher Games yang dikenal dengan Digital Eight

\section{Kesimpulan}

Kelompok Kompas Gramedia yang telah berhasil dalam bidang media massa, melakukan spasialisasi guna menjadikan produk-produknya yang mengglobalisasi. Dengan produk media majalah Intisari yang pertama kali terbitt di tahun 1963, Kompas Gramedia melakukan banyak komodifikasi produk sehingga menghasilkan produkproduk yang mengglobalisasi. Seperti yang diungkapkan oleh Mosko, bahwa Ekonomi Politik terbagi menjadi tiga konsep yakni, komodifikasi, spasialisasi dan Globalisasi, konsep ini telah dijalankan oleh Kompas Gramedia Group agar dapat terus menciptakan inovasi media dan produkproduk perusahaan lainnya dalam mempertahankan eksistensi Perusahaan.

Kegiatan Ekopol ini, memiliki segi negatif, misalnya, kemampuan pemilik perusahaan untuk mengintervensi kebijakan pemerintah dalam mencapai tujuan pribadi perusahaan. Namun menurut penulis, Kompas Gramedia Group tidak melakukan intervensi untuk kepentingan perusahaan, 
sebagai contoh, dalam Pemilihan Presiden tahun 2014 yang lalu, Koran Kompas tidak memberitakan informasi yang memihak salah satu calon Presiden 2014, yakni antara Jokowi dan Prabowo. Walaupun terjadi konglomerasi dari ranah kepemilikan, Kompas masih memperlihatkan profesionalitasnya dalam kualitas isi berita maupun penempatan Judul Berita yang sesuai dengan kaidah Kesopanan. Karena sejatinya, media harus terus memberi informasi yang sesuai dengan fakta, tanpa keberpihakan.

Sebagai masukan, Kelompok Kompas Gramedia yang telah melakukan spasialisasi sehingga menghasilkan produk yang mengglobal, diharapkan konten-konten isi berita yang menggunakan satu sumber untuk tiga jenis teknologi media, yakni media cetak, elektronik (televisi, radio) dan internet. Isi berita yang dipaparkan nyaris sama dari penulisan, bahasa dan sumber berita. Sehingga diharapkan kedepan, teknologi yang berkembang membuat setiap awak media mengimbangi perkembangan teknologi tersebut, dengan cara menyajikan berita yang walaupun dengan kasus yang sama, namun pemaparan bisa dengan nara sumber yang berbeda, dan pendidikan bagi wartawan agar kemampuan dalam menulis berita lebih akurat.

\section{Daftar Pustaka}

Mcquail, D. (2012). Teori Komunikasi Massa, edisi 6. Jakarta: Salemba Humanika

Mosco, Vincent. (2009). The Political Economy of Communication, $2^{\text {nd }}$ Edition. London: Sage Publications

Wikipedia.(2015). https://id.wikipedia.org/wiki/Kompas
_Gramedia, diakses pada tanggal 21

Desember 2015 pukul 16.00

InfospesialNEWS(http://www.infospesial.net/315/1 2-media-besar-kuasai-indonesia/). diakses pada tanggal 12 Juli 2015 pukul 13.00 